\title{
A Patient with Severe Malaria and COVID-19: How Do You Tell the Difference between These Infections?
}

\author{
Maria João Correia ${ }^{1,2}$, Luciana Frade ${ }^{1,2}$, Renato Guerreiro ${ }^{1,2}$, Inês Araujo ${ }^{1,2}$, Teresa Baptista ${ }^{1,3}$, \\ Cândida Fonseca ${ }^{1,2}$, Kamal Mansinho ${ }^{1,3}$ \\ ${ }^{1}$ COVID Department, Hospital São Francisco Xavier, Lisboa, Portugal \\ ${ }^{2}$ Internal Medicine Department, Hospital São Francisco Xavier, Lisboa, Portugal \\ ${ }^{3}$ Infectious Diseases Department, Hospital Egas Moniz, Lisboa, Portugal
}

Received: $16 / 09 / 2020$

Accepted: $20 / 10 / 2020$

Published: $13 / 11 / 2020$

How to cite this article: Correia MJ, Frade L, Guerreiro R, Araujo I, Baptista T, Fonseca C, Mansinho K. A patient with severe malaria and COVID-1: how do you tell the difference between these infections? EJCRIM 2020;7: doi:10.12890/2020_002007.

Conflicts of Interests: The Authors declare that there are no competing interests.

Acknowledgements: We gratefully acknowledge our patient.

This article is licensed under a Commons Attribution Non-Commercial 4.0 License

\section{ABSTRACT}

Coronavirus infection, known as COVID-19, is characterized by clinical, epidemiological and biological features similar to those of malaria. In each case, fever, myalgia, fatigue, headaches and gastrointestinal symptoms may be present. Both diseases can also induce a cytokine storm and pro-coagulant states. An appropriate epidemiological approach and differential diagnosis are very important so that the right clinical intervention can be selected.

Malaria remains a serious global public health issue, especially in endemic countries. Elimination campaigns are helping to control the disease, but in many countries these programs are now at risk of failure due to logistic and economic problems caused by COVID-19.

The authors describe the case of a patient with co-infection with malaria and COVID-19, reminding us that during this coronavirus pandemic it is critical to consider other diagnoses, particularly in people traveling between countries.

\section{LEARNING POINTS}

- As far as we know, this is one of the first case reports of co-infection with COVID-19 and Plasmodium falciparum malaria.

- It is important to be aware of the clinical challenges of diagnosing the cause of fever in returned travellers.

\section{KEYWORDS}

COVID-19, SARS-CoV-2, malaria, Plasmodium falciparum

\section{CASE DESCRIPTION}

A 47-year-old black male entrepreneur who frequently travelled between Portugal and Angola, returned from Africa 10 days before hospital presentation. He was admitted to the emergency department due to a 5-day history of diarrhoea (>5 episodes daily), worsening malaise, high fever, diaphoresis and occasional dry cough. He had no previous medical history, did not use drugs, did not have any addictions, and had not been in contact with anybody infected with COVID-19.

At hospital admission, the patient was conscious, febrile and tachycardic but haemodynamically stable. Physical examination was normal, without signs of dehydration, respiratory changes or abdominal discomfort. The initial blood work revealed mild anaemia (haemoglobin 
$12.1 \mathrm{~g} / \mathrm{dl}$ ), lymphopenia (lymphocytes $1260 \times 10^{9} / \mathrm{l}$ ), thrombocytopenia (platelets $91 \times 10^{9} / \mathrm{l}$ ) and elevated inflammatory parameters (C-reactive protein $25.1 \mathrm{mg} / \mathrm{dl}$, ferritin $789 \mathrm{ng} / \mathrm{ml}$ ), but no other abnormalities such as renal or hepatic changes. An HIV test was negative. A nasopharyngeal swab for SARS-CoV-2 PCR testing was positive, as were total antibody titres against SARS-CoV-2 detected using chemiluminescence assays (CLIA). A chest $x$-ray did not show any pleural effusions, lung consolidation or interstitial patterns.

After he was diagnosed with SARS-CoV-2 infection, the patient was admitted to a COVID ward for further observation and symptom control. On the third day, he was still myalgic, generally unwell and febrile, despite being on antipyretics. Given the epidemiological history and the persistence of symptoms, a rapid diagnostic test for malaria parasite antigens was requested, and showed a positive result. Blood smear identified trophozoites of Plasmodium falciparum with a parasitaemia of 3.1\% (parasite level of 83,520 parasites/ $\mu$ l). The patient did not meet any of the criteria for severe disease, and therapy with a combination of artemether and lumefantrine was administered. After 24 hours of treatment, symptoms completely resolved and the patient became afebrile. The platelet count normalized, and there was a consistent reduction in inflammatory parameters. Three days later, control microscopy revealed a parasitaemia of $0.3 \%$, and on the sixth day the blood smear was negative for $P$. falciparum. The patient did not show any progressive respiratory symptoms, including decreased oxygen levels, or radiographic findings suggestive of SARS-CoV-2 infection. He was discharged completely asymptomatic 14 days after COVID-19 diagnosis.

\section{DISCUSSION}

In this time of pandemic, fever in a patient who has visited a different country remains a diagnostic challenge, and a wide differential diagnosis must be considered ${ }^{[1-3]}$.

Our patient presented to the emergency room with diarrhoea, fatigue and fever. He had few respiratory symptoms and no pathological radiographic changes. Since he met multiple criteria for SARS-CoV-2 infection, he was tested and was admitted to hospital for surveillance. However, a diagnosis of malaria was also made based on evidence of travel to a malaria-endemic country, persistent fever and blood smear results.

The present case report highlights the danger of focusing only on a diagnosis of COVID-19, which may lead to rapid and fatal clinical worsening due to inadequate treatment of a different condition. It reminds us how important it is to consider the patient's history, their travel history and the epidemiological context. Even in a pandemic, taking a good personal history is essential and alternative diagnoses should be considered ${ }^{[4]}$.

\section{REFERENCES}

1. Nghochuzie NN, Olwal CO, Udoakang AJ, Amenga-Etego LN, Amambua-Ngwa A. Pausing the fight against malaria to combat the COVID-19 pandemic in Africa: is the future of malaria bleak? Front Microbiol 2020;11:1476.

2. Sardar S, Sharma R, Alyamani TYM, Aboukamar M. COVID-19 and Plasmodium vivax malaria co-infection. IDCases 2020;21:e00879.

3. Gutman JR, Lucchi NW, Cantey PT, Steinhardt LC, Samuels AM, Kamb ML, et al. Malaria and parasitic neglected tropical diseases: potential syndemics with COVID-19? Am J Trop Med Hyg 2020;103(2):572-577.

4. Rogerson SJ, Beeson JG, Laman M, Poespoprodjo JR, William T, Simpson J, et al. Identifying and combating the impacts of COVID-19 on malaria. BMC Med 2020;18:239. 